See discussions, stats, and author profiles for this publication at: https://www.researchgate.net/publication/319911556

\title{
A Complete Mathematical Modeling, Simulation and Computational Implementation of Boost Converter Via MATLAB/Simulink
}

Article in International Journal of Pure and Applied Mathematics · March 2017

2 authors, including:

Q.

Viswanatha v.

Acharya Institute of Technology Bangalore

10 PUBLICATIONS 8 CITATIONS

SEE PROFILE

Some of the authors of this publication are also working on these related projects:

Project Control of Bidirectional buck boost converter using Microcontrollers View project

Project Watering the field automatically based on the moisture level of the soil View project 


\title{
A Complete Mathematical Modeling, Simulation and Computational Implementation of Boost Converter Via MATLAB/Simulink
}

\author{
Viswanatha $\mathrm{V}^{1}$ and Venkata Siva Reddy $\mathrm{R}^{2}$ \\ ${ }^{1}$ School of Electrical and Electronics \\ Engineering, REVA University Bangalore, \\ Karnataka, India. \\ vishwanathv@revainstitution.org \\ 2 School of Electronics and Communication \\ Engineering, REVA University Bangalore, \\ Karnataka, India. \\ venkatasivareddy@reva.edu.in
}

May 27, 2017
Corresponding author: Vishwanatha V
Email: vishwanathv@revainstitution.org
Mobile: 9741236462

\begin{abstract}
This paper describes mathematical modeling techniques, simulation and implementation of boost converter. Four modeling techniques such as circuit modeling, mathematical circuitry modeling, and transfer function modeling and state-space modeling. Each modeling method is developed and implemented in MATLAB and Simulink environment. Circuit modelling is also done in PSIM tool. From the simulation results it is clear that capacitor voltage waveform which is a state variable gives identical response in all modeling techniques; state-space, mathematical circuitry, circuit and transfer function modeling approaches. Simulation results of all models perfectly overlapping each other and also settling time is very less in circuit modeling and transfer function modeling which is more desirable .Stability analysis ; bode plot ,pole-zero plot and step response are carried out using transfer function modeling .The offered models helps to the expansion of boost converter design, simulation ,analysis and educational tool[1].

Key Words : boost converter; modelling techniques; transfer function modelling; mathematical circuitry modelling; state-space modeling ; circuit modelling.
\end{abstract}

\section{Introduction}

Now a days digital controller design plays an important in the 
more importance because of its advantages like flexibility and cost and systems can be made smart systems due to usage of digital controller which can be programmed[2]. Programming of such controlled can be done with the usage of mathematical equations like differential equations, algebraic equations and Laplace transform[3].that is how the importance of mathematical modelling coming into picture.

Mathematical modeling of circuit has total control over the simulation process that gives a smaller execution time.On the other hand it takes long time for the initial setup as the user has to develop all possible compostion of differential and algebraic equations that results in troubleshooting and debugging of codes developed with the mathematical models but for circuit modeling setup time is small in the beginning and the changes can be made easily[4]. On the other side, it has little control on the simulation process that results in long simulation time. In comparison of all models, mathematical circuitry technique has a total control over the model and there is no limitation about the model and on the other hand it is difficult to implement the hardware, in addition to this it is difficult to model non-ideal model but most important thing is it is restricted to time domain analysis only. When it comes to transfer function technique it is not difficult to simulate and implement and very important thing is that here both time domain and frequency domain analysis can be made so here because of frequency domain modeling system can be studied with respect to its stability analysis and hence the performance of the system can be estimated so that is the advantage of this modeling technique. On the other hand it is applicable only for single input and single output model and also it is difficult for nonideal model and it requires supplementary tool box for text programming. When it comes to state-space modeling it is exactly same as transfer function modeling with respect to pros and cons, however state space modeling allows to model the system with multiple input and multiple output.

When it comes to literature survey, there are many types of modeling followed by simulation literatures which are there for boost converter but it is only for non-ideal so it will not be good for education[7]. As of now no literature gives complete modeling followed by simulation and their computational implementation techniques for boost converters but here all four modeling techniques followed by their simulation along with their computational implementation are done for boost converter and results are clearly shows that they are perfectly overlapping each other. There are many simulation tools like PSim,MATLAB,PSpice,PSCAD and so on are available in the market for power converter modeling and simulation. But in this paper MATLAB/Simulink is used to do modeling and simulation under one platform for all four modeling techniques. 
It is a major method of modeling and simulation of systems which oversee the laws of physics. Different forms of assumption may be considered in mathematical modeling process based on the particular scenario .State space modeling technique is used for optimal control problems whereas transfer function technique is used for transient response or frequency response analysis of SISO[6].transfer function modeling technique is preferred than any other modeling technique. As soon as mathematical model is derived for the given system various computational methods can be used synthesis and analysis.

Here mathematical model is obtained for the boost converter circuit based on theory of its working principle. In this paper ideal model of non-isolated DC-DC Boost converter is considered for simplifying the complexity of modeling.Fig. 1 shows the basic boost converter and it is used in this entire paper for all four modeling techniques[7]. The boost converter is made with two energy storage elements, one $\mathrm{n}$-channel MOSFET and one diode. During switching process MOSFET and diode work compliment to one another i.e. When MOSFET is ON diode is OFF and when diode is ON, MOSFET is $\mathrm{OFF}$ at a given interval of time.

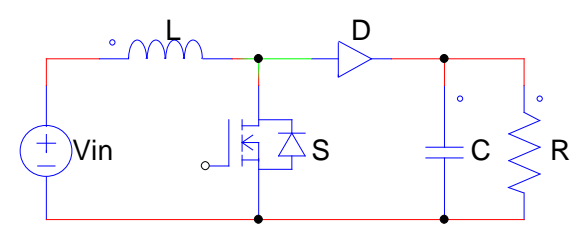

Fig. 1. Boost converter circuit diagram

The mathematical modeling begins with storage elements capacitor and inductor in the boost converter as shown in Fig.1. inductor voltage and capacitor current are given in eqn (1) and (2) respectively.

$$
\begin{aligned}
& v_{L}=L \frac{d i_{L}}{d t} \\
& i_{c}=c \frac{d v_{c}}{d t}
\end{aligned}
$$

The boost conversion begins when the switching process starts, which results in two forms of circuits as shown in Fig 2a.and Fig. 2b

While inductor $\mathrm{V}_{\mathrm{L}}$ for switching condition of $\mathrm{ON}$ and $\mathrm{OFF}$ are shown in (3) and (4) respectively.

$$
v_{L}=v_{i n} * P W M
$$




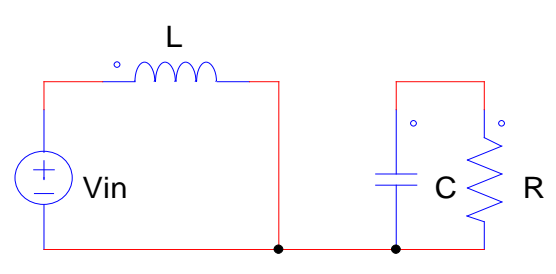

MOSFET 'ON' condition

Fig. 2a. Boost converter in $\mathrm{ON}$ state during operation

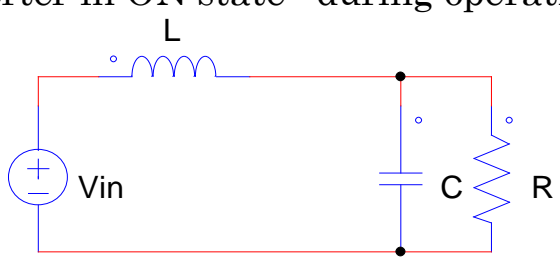

MOSFET 'OFF' condition

Fig. 2b. Boost converter in OFF state during operation

$$
v_{L}=\left(v_{\text {in }}-v_{\text {out }}\right) * \overline{P W M}
$$

The switching time between (3) and (4) is determined by the PWM switching frequency and its duty cycle shows in (5), here duty cycle is the ratio of $\mathrm{V}_{0}-\mathrm{Vin}$ to $\mathrm{V}_{0}$.

$$
P W M=\frac{\left(v_{o}-v_{i n}\right)}{v_{o}} f_{p w m}^{-1}
$$

The current flowing through can be determined by integrating in (6).

$$
i_{L}=\frac{1}{L} \int v_{L} d t
$$

After obtaining, the current through the capacitor can be determined in (7), where is the current through load resistor.

$$
i_{C}=i_{L}-i_{R}
$$

After obtaining iC, the capacitor voltage can be calculated in (8), which indicates the load voltage of the boost converter in case of ideal model.

$$
v_{C}=\frac{1}{C} \int i_{C} d t
$$

The mathematical modeling approach includes graphical implementation method where data flow is

drawn in Simulink platform. it actually links the differential equation in a graphical manner to model the boost converter system which is as shown in Fig.3.Basic laws of KVL and KCL are applied for $\mathrm{ON}$ and $\mathrm{OFF}$ states of boost converter and obtained 
states[8].Upon these two equations graphical computational model is implemented and it is as showninFig. 3

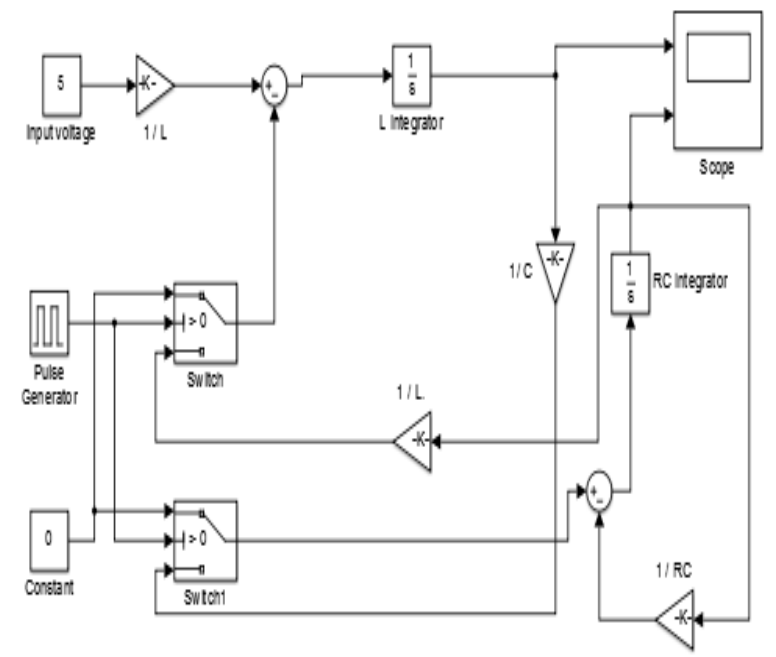

Fig. 3.Mathematical model graphical computational implementation

\section{Circuitry Modeling}

It is a graphical method of representing the system in terms of circuit diagram which consists of apparatus which are interconnected with each other to form the system. Circuit modeling is carried out in SimPowerSystems of Simulink and PSIM which are two different simulation environments. Fig 4 and Fig 5, shows the circuit modelling of boost converter using SimPowerSystems and PSIM respectively.

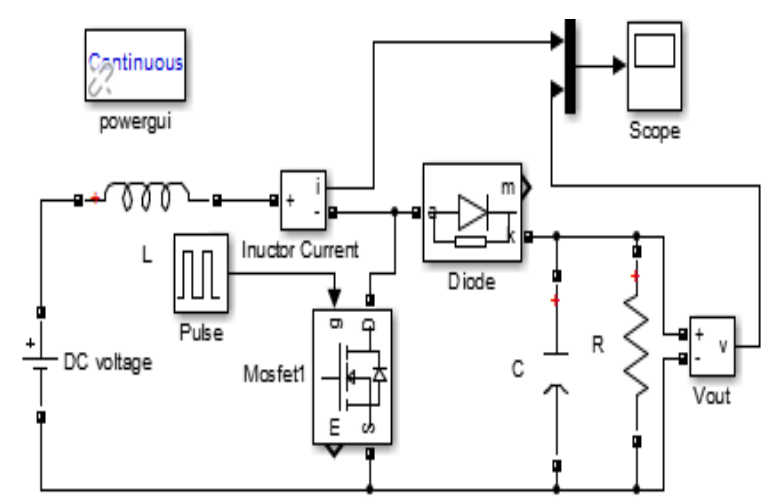

Fig.4.Boost converter model in SimPowerSystems 


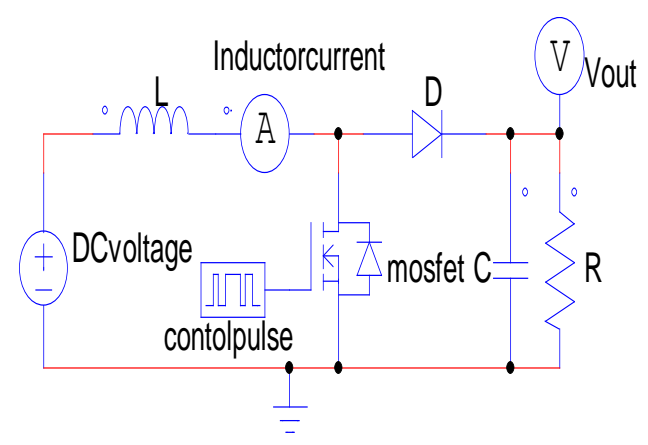

Fig.5.Boost converter model in PSIM

PSIM tool is good for schematic circuit simulation whereas SimPower Systems can be used for both schematic circuit simulation and differential equations to solve the model and simulation.

\section{Transfer Function Modeling}

Boost converter is modelled in S-domain using transfer function modeling technique. By referring boost converter when switch is OFF the total impedance can be given by the following equation.

$$
Z_{\text {total }}=Z_{1}(S)+Z_{2}(S)
$$

$\mathrm{Z} 1(\mathrm{~S})$ is given by

$$
\begin{aligned}
& \frac{\operatorname{Vin}(S)}{I(S)}=Z_{1}(S)=\left(R \square \frac{1}{C S}\right)+L s \\
& \frac{\operatorname{Vin}(S)}{I(S)}=\frac{R C L s^{2}+L s+R}{R C s+1}
\end{aligned}
$$

Inductor current is given by

$\mathrm{Z}_{2}(\mathrm{~S})$ is given by

$$
I(S)=\frac{R C s+1}{R C L s^{2}+L s+R} . \operatorname{Vin}(S)
$$

$$
\frac{V_{\text {OUT }}}{I(S)}=Z_{2}(S)=\frac{R}{R C s+1}
$$

Therefore transfer function is given by

$$
\frac{V_{\text {OUT }}}{V_{I N}}=\frac{R}{R C L s^{2}+L s+R}
$$

Equation 12 and 14 are implemented in functional block of the transfer function as shown in fig.6. 


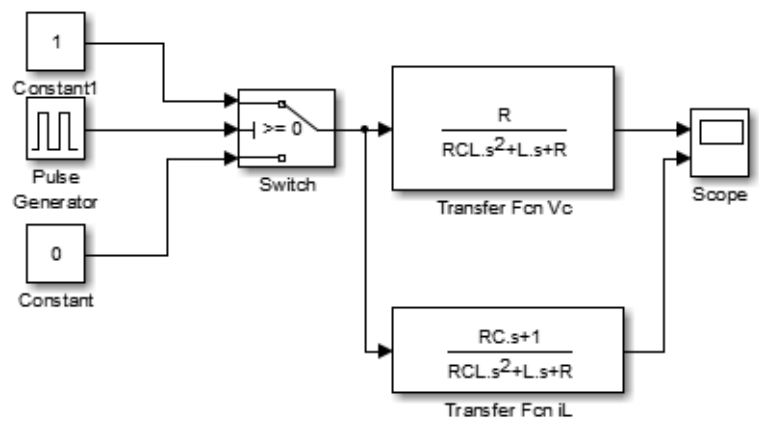

Fig.6.Transfer function model in functional block implementation

Transfer function modeling technique for boost converter allows to analyse the stability of the boost converter thoroughly with system responses such as step, bode plot, pole and zero responses which are obtained from MATLAB Functions such as step(,bode) and pzmap() respectively.Fig.7 shows the pole zero plot, step response and bode plot.

Pole Zero Map

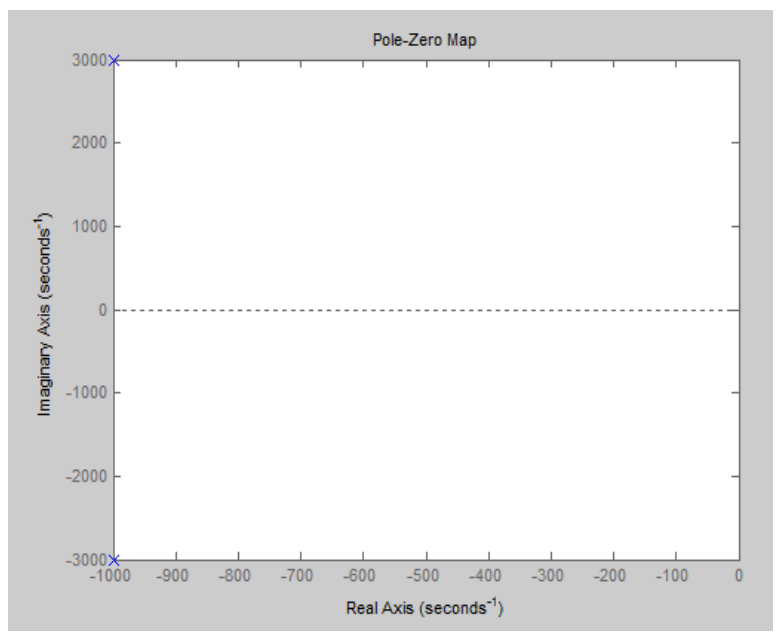

Step Response

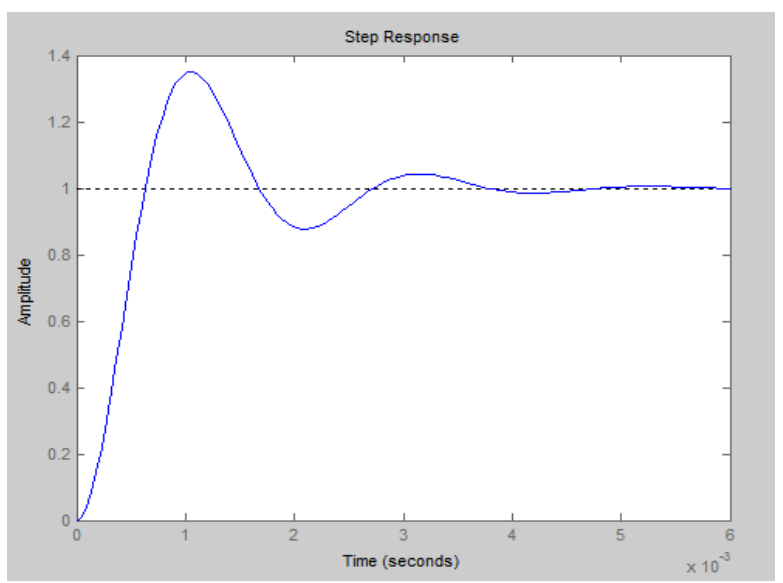

Bode Diagram 


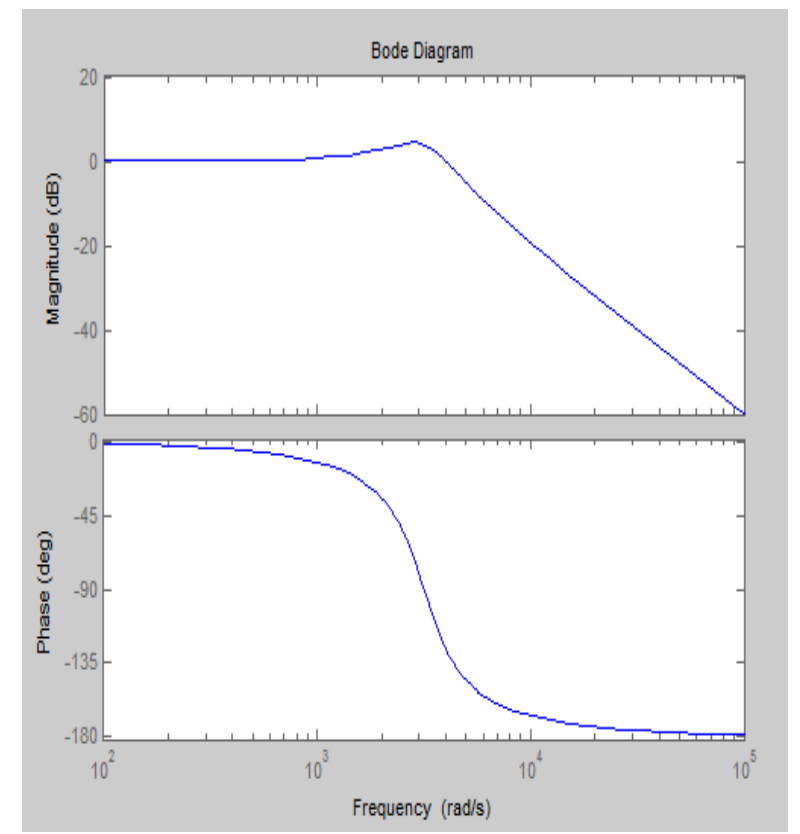

Fig.7.Boost converter pole \& zero map, step response and bode plot.

\section{State Space Modeling}

Boost converter is modelled by using state space modeling technique which helped to analyse the boost converter in both time as well as frequency domain[9]. In state space modeling the state matrix are represented by A,B.C and D, X is the state variable, is state variable derivative , $U$ is the input and $\mathrm{Y}$ is the output. Here average large signal modeling is used to get state space model of boost converter.

$$
\begin{aligned}
& \dot{X}=A^{*} X+B^{*} U \\
& Y=C^{*} X+D^{*} U
\end{aligned}
$$

When switch in boost converter is $\mathrm{ON}$, the state variable and output $\mathrm{Y}$ are obtained as

$$
\begin{gathered}
\dot{X}=\left[\begin{array}{c}
\frac{d I_{L}}{d t} \\
\frac{d V}{c} \\
d t
\end{array}\right]=\left[\begin{array}{cc}
0 & 0 \\
0 & \frac{-1}{R C}
\end{array}\right] *\left[\begin{array}{l}
I_{L}(t) \\
V_{C}(t)
\end{array}\right]+\left[\begin{array}{c}
\frac{1}{L} \\
0
\end{array}\right] *\left[V_{i n}\right] \\
Y=\left[\begin{array}{ll}
0 & 1
\end{array}\right] *\left[\begin{array}{c}
I_{L} \\
V_{C}
\end{array}\right]+[0] *\left[V_{\text {in }}\right]
\end{gathered}
$$

When switch in boost converter is OFF, the state variable 


$$
\begin{aligned}
& \dot{X}=\left[\begin{array}{c}
\frac{d I_{L}}{d t} \\
\frac{d V_{C}}{d t}
\end{array}\right]=\left[\begin{array}{cc}
0 & \frac{-1}{L} \\
\frac{1}{C} & \frac{-1}{R C}
\end{array}\right] *\left[\begin{array}{l}
I_{L}(t) \\
V_{C}(t)
\end{array}\right]+\left[\begin{array}{c}
\frac{1}{L} \\
0
\end{array}\right] *\left[V_{i n}\right] \\
& Y=\left[\begin{array}{ll}
0 & 1
\end{array}\right] *\left[\begin{array}{l}
I_{L}(t) \\
V_{C}(t)
\end{array}\right]+[0] *\left[V_{\text {in }}\right]
\end{aligned}
$$

By applying averaging technique to the equations (17),(18),(19) and (20), average large signal state space model is obtained as follows

$$
\begin{gathered}
\dot{\mathrm{X}}=\left[\begin{array}{cc}
0 & \frac{-(1-d)}{L} \\
\frac{(1-d)}{C} & \frac{-1}{R C}
\end{array}\right] *\left[\begin{array}{c}
I_{L}(t) \\
V_{C}(t)
\end{array}\right]+\cdot\left[\begin{array}{c}
\frac{1}{L} \\
0
\end{array}\right] * V_{i n} \\
Y=\left[\begin{array}{ll}
0 & 1
\end{array}\right] *\left[\begin{array}{l}
I_{L}(t) \\
V_{C}(t)
\end{array}\right]+[0] . V_{\text {in }}
\end{gathered}
$$

Equation 21 and 22 are implemented in state space functional block as shown in fig. 8

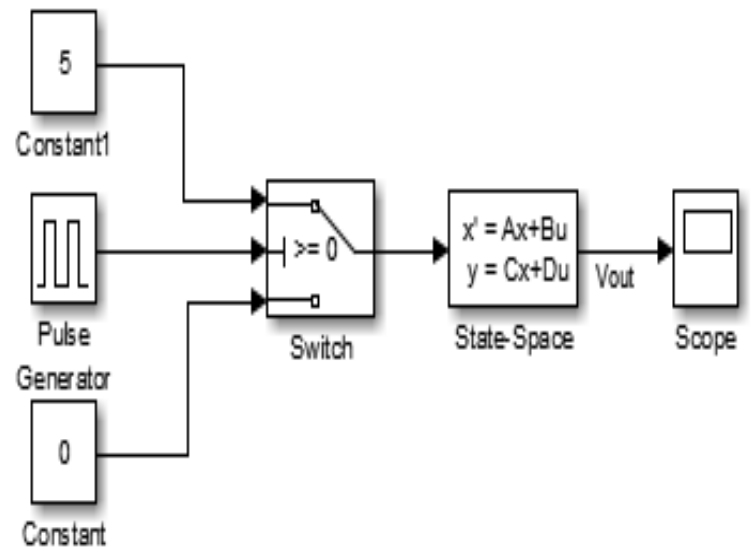

Fig.8.State space model in functional block implementation 
Four modeling methods are done for boost DC-DC converter and same models are simulated in MATLAB/Simulink in section II,III,IV and V. The simulation results for all four modeling techniques are shown in fig.9.a and fig.9.b. The simulation results are based on the following specifications, $\mathrm{R}=10 \Omega, \mathrm{C}=100 \mu \mathrm{F}, \mathrm{L}=1 \mathrm{mH}, \mathrm{F}=50 \mathrm{KHz}$, Duty Cycle $=50 \%$ and Vin $=5 \mathrm{~V}$.

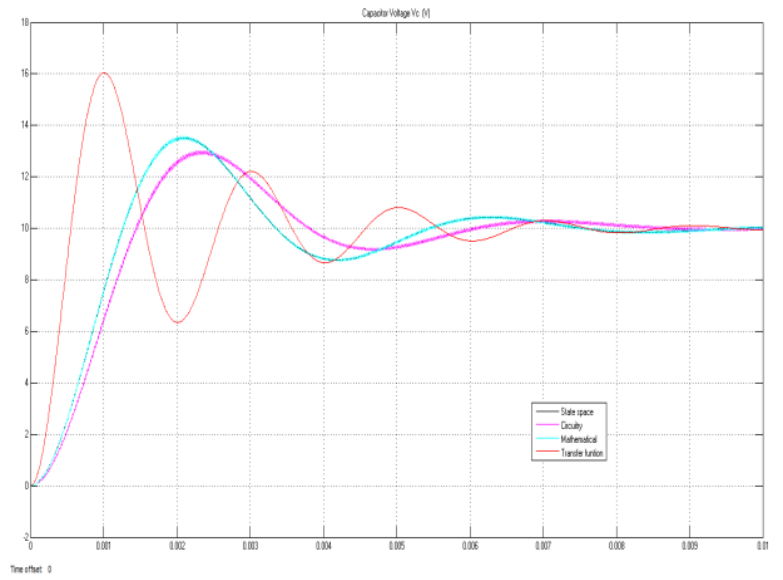

Fig.9a.Simulation results for all four modelling approaches (capacitor voltage)

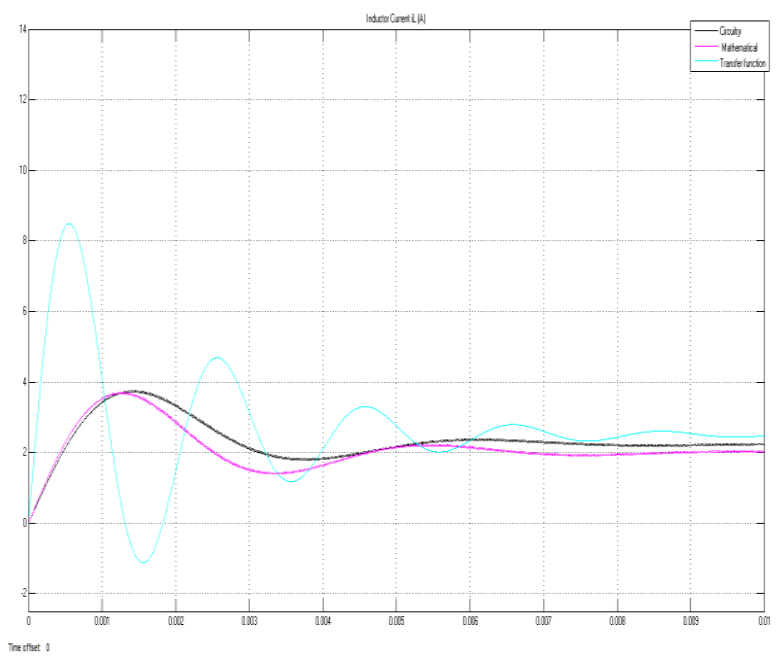

Fig.9b.Simulation results for all modelling approaches (inductor current)

\section{Conclusion}

Over all, four modeling techniques such as state space modeling, transfer function modeling, circuit modeling and mathematical modeling are done for boost converter and presented in this paper. The Simulation results for all four, modeling techniques are also presented. Simulation results of all models perfectly overlapping each other and also settling time is less in circuit modeling and transfer function modeling which is more desirable. Moreover mathematical modeling techniques find more scope in digital controller design for dc-dc 
It gives complete outline of boost converter modeling and its simulation by applying mathematical concepts such as differential equations, circuit theory, control theory, s-domain, signal and systems for DC-DC converter.

\section{REFERENCES}

[1] Rodney H.G TanI. , Matthew Y.W.Teow," A Comprehensive Modeling,Simulation and Computational Implementation of Buck Converter Using MATLAB/Simulink" ,Energy Conversion(CENCON)”,2014 IEEE Conference on 13-14 Oct.2014, pp. 37-42.

[2] R.A. Kordkheili, M. Yazdani-Asrami, A.M. Sayidi, "Making DC-DC Converters Easy to Understand for Undergraduate Students", IEEE Conference on Open Systmes (ICOS), 2010, pp. 28-33

[3] L.S. Patil, K.D. Patil, A.G. Thosar,'The Role of Computer Modeling and Simulation in Power Electronics Education", IEEE 2nd International Conference on Emerging Trends in Engineering and Technology (ICETET), 2009, pp.416-419.

[4] C.A. Canesin, F.A.S. Goncalves, L.P Sampaio, "Simulation Tools of DCDC Converters for Power Electronics Education", 13th European Conference on Power Electronics and Applications (EPE), 2009, pp. 1-10

[5] I.H. Baciu, I. Ciocan, S. Lungu, "Modeling Transfer Function for Boost Power Converter", 30th International Spring Seminar on Electronics Technology, May 2007, pp. 541-544.

[6] A.W.N. Husna, S.F. Siraj, M.Z. Ab Muin, "Modeling of DC-DC Converter for Solar Energy System Applications", IEEE Symposium on Computers \& Informatics (ISCI), 2012, pp. 125-129.

[7] Monamed. A. Shrud, Ahmad Kharaz, Ahmed. S. Ashur, Mustafa Shater, Ismail Benyoussef, "A Study of Modeling and Simulation for Interleaved Boost Converter", Power Electronic \& Drive Systems \& Technologies Conference (PEDSTC), 2010, pp. 28-35.

[8] S. Laali, H.M Mahery, "Buck DC-DC Converter: Mathematical Modeling and Transient State Analyzes", 3rd IEEE International Symposium on Power Electronics for Distributed Generation Systems (PEDG), 2012, pp. 661-667.

[9] A.J. Forsyth, S.V. Mollov, "Modeling and Control of DC-DC Converters" IEE Power Engineering Journal, vol. 12, no. 5, pp. 229236 , October 1998. 
